\title{
DESAIN SARANA PENGISI DAYA PONSEL DI DIREKTORAT POLITEKNIK NEGERI SAMARINDA
}

\author{
Dwi Cahyadi \\ Staf Pengajar Program Studi Desain Produk, Jurusan Desain \\ Politeknik Negeri Samarinda \\ e-mail: dwi_polnes@yahoo.co.id \\ Lolita Mariska \\ Mahasiswa Program Studi Desain Produk, Jurusan Desain \\ Politeknik Negeri Samarinda
}

\begin{abstract}
ABSTRAK
Kehidupan manusia sehari-hari tidak terlepas dari kebutuhan untuk berkomunikasi. Salah satu alat yang biasa digunakan untuk berkomunikasi jarak jauh adalah handphone. Teknologi handphone yang mengadopsi teknologi mutakhir disebut sebagai smartphone. Smartphone merupakan kebutuhan masyarakat yang memiliki banyak manfaat, memudahkan pekerjaan, dan meningkatkan gaya hidup. Smartphone tidak bisa terus menerus digunakan. Smartphone membutuhkan daya untuk untuk bisa menyala dan digunakan. Pengisi baterai atau battery charger adalah piranti yang digunakan untuk mengisi ulang energi ke dalam baterai dengan memasukkan arus listrik melaluinya. Namun ada banyak kendala yang sering dialami ketika kita harus seharian berada di luar rumah, penyedia daya listrik yang terbatas di tempat umum membuat kita sulit mengisi ulang baterai smartphone. Kebutuhan pengisian baterai terus meningkat seiring dengan pemakaian listriknya. Inovasi baru yang menjadi perhatian adalah seperti pada sarana pengisian baterai pada tempat umum seperti Institusi Pendidikan. Salah satunya adalah Politeknik Negeri Samarinda. Ketika berada di tempat umum dan baterai smartphone lemah, berdasarkan pada aspek kenyamanan, jenis smartphone dan tempat untuk mengisi daya baterai smartphone. Oleh karena itu untuk merancang sebuah produk yaitu desain sarana charging station yang nyaman dan terdapat berbagai jenis charger yang mampu memudahkan pengunjung untuk mengisi baterai smartphone, maka dibuatlah sarana Charging Station Direktorat Politeknik Negeri Samarinda.
\end{abstract}

Kata kunci: Smartphone, charger, Institusi Pendidikan. 
Vol. 5, No. 2, April 2018

\section{ABSTRACT}

Everyday human life is inseparable from the need to communicate. One of the tools commonly used to communicate remotely is mobile. Mobile technology that adopts cutting edge technology is called smartphone. Smartphones are the needs of people who have many benefits, facilitate work, and improve lifestyle. Smartphones can not be used continuously. Smartphones require power to be able to power up and use. A battery charger or battery charger is a device used to recharge energy into the battery by entering an electric current through it. But there are many obstacles that are often experienced when we have to spend the day outside the house, providing limited electricity in public places makes it difficult for us to recharge smartphone bat teries. The need for battery charging continues to increase along with its power consumption. The new innovation of concern is like the means of charging batteries in public places such as the Institute of Education. One of them is the Samarinda State Poly technic. While in public and smartphone batteries are weak, based on convenience aspect, smartphone type and place to charge smartphone battery. Therefore, to design a product that is a convenient means of charging station design and there are various types of chargers that can facilitate visitors to charge the smartphone battery, then made a means Charging Station Directorate of State Polytechnic Samarinda.

Keywords: Smartphone, Charger, Institute of Education.

\section{Pendahuluan}

Kehidupan manusia sehari-hari tidak terlepas dari kebutuhan untuk berkomunikasi antara yang satu dengan yang lain. Salah satu alat yang biasa digunakan untuk berkomunikasi jarak jauh adalah telepon genggam atau handphone. Teknologi handphone yang mengadopsi teknologi yang mutakhir disebut sebagai smartphone.

Smartphone merupakan salah satu kebutuhan masyarakat yang memiliki banyak manfaat, salah satunya untuk memudahkan pekerjaan, dan meningkatkan gaya hidup. Namun smartphone tidak bisa terus menerus digunakan. Smartphone membutuhkan daya untuk bisa menyala dan digunakan. Pentingnya charger untuk smartphone adalah untuk mengisi daya baterai smartphone yang lemah agar bisa digunakan kembali.

Pengisi baterai atau battery charger adalah piranti yang digunakan untuk mengisi energi ke dalam baterai (isi ulang) dengan memasukkan arus listrik melaluinya. Arus listrik yang dimasukkan tergantung pada teknologi dan kapasitas baterai yang dapat diisi ulang tersebut.

Namun ada banyak kendala yang sering dialami ketika kita harus seharian berada di luar rumah, penyedia daya listrik yang terbatas di tempat umum membuat kita sulit mengisi ulang baterai smartphone. Kebutuhan pengisian baterai terus meningkat seiring dengan pemakaian listriknya. Inovasi baru yang menjadi perhatian adalah seperti pada sarana pengisian baterai pada tempat umum Institusi Pendidikan, salah satunya adalah Politeknik Negeri Samarinda.

Oleh karena itu perlu dirancang sebuah produk yaitu desain sarana charging station yang nyaman dan terdapat berbagai jenis charger smartphone yang mampu memudahkan pengunjung untuk mengisi baterai smartphone, maka dibuatlah sarana charging station Direktorat Politeknik Negeri Samarinda.

\section{Metode Perancangan}

Dalam merancang atau mendesain sebuah produk ini agar perancangan lebih terarah, penulis menggunakan metode perancangan Goel Vinod (1995) dengan langkah-langkah seperti berikut, yaitu: 


\subsection{Perumusan Masalah}

Yaitu belum adanya charging station atau pengisian daya baterai smartphone di Direktorat Politeknik Negeri Samarinda.

\subsection{Tinjauan Pustaka}

Meliputi Studi eksisting yang terdiri dari definisi eksisting beserta jenis fasilitas charging stationyang sudah ada.. Teori segmentasi terdiri dari segementasi geografis, segmentasi demografis, segmentasi psikografis, segmentasi perilaku dan segmentasi manfaat. Teori ergonomi dan anthropometri, teori system, teori material, teori bentuk, dan teori warna.

\subsection{Analisis \& Spesifikasi Desain}

Meliputi Analisis pasar, studi aktifitas dan kebutuhan, analisis ergonomi \& anthropometri, analisis konfigurasi, analisis material, analisis bentuk, analisis warna dan analisis produksi. Dan spesifikasi desain (pengguna, dimensi, komponen, konfigurasi, sistem, material, bentuk, dan warna) untuk charging station di Direktorat Politeknik Negeri Samarinda.

\subsection{Alternatif Desain}

Dibuat beberapa sktesa alternative desain awal. Selanjutnya desain awal ini dianalisa sesuai krietria desain yang telah ditetapkan, tuntuk dipilih alternative desain terpilih.

\subsection{Pengembangan Alternatif desain}

Pengembangan dari alternative desain awal yang terpilih. Dikembangkan menjadi beberapa sketsa pengembangan. Sketsa sketsa tersebut dianalisis untuk dicapai pemenuhan kriteria desain, sehingga terwujud desain final.

\subsection{Final design dan Prototyping}

Yaitu penjabaran hasil dari desain final, berupa gambar presentasi, gambar teknik, gambar urai, modeling produk, animasi dan prototype produk.

\section{Pembahasan \\ 3.1. Studi Aktivitas dan Kebutuhan}

Analisis aktivitas dan kebutuhan dilakukan untuk mengetahui aktivitas-aktivitas yang dilakukan berkaitan dengan produk yang akan dibuat sehingga diperoleh daftar kebutuhan pengguna. Berdasarkan kebutuhan tersebut maka dibuatlah pemecahan dalam memenuhi kebutuhan tersebut dan mengaplikasikannya pada produk.

Berdasarkan analisis aktivitas dan kebutuhan hasil analisis, maka didapatkan kesimpulan mengenai komponen-komponen apa saja yang harus ada dalam produk, ialah: Memiliki charger untuk mengisi baterai smartphone, memiliki aksen motif lokal sebagai identitas budaya lokal Kaltim, memiliki tempat meletakan smartphone yang sedang di charge, dan memiliki bidang datar peletakan informasi dan penutup akrilik untuk tempat informasi.

\subsection{Analisis Ergonomi dan Anthopome- tri}

Analisis ergonomi dilakukan untuk meminimalkan resiko kesehatan dan keselamatan dan juga agar kenyamanan dalam melakukan kegiatan menggunakan produk dapat maksimal. Ergonomi sangat diperlukan untuk merancang suatu produk.Aktifitas-aktifitas yang telah dianalisis membutuhkan fasilitas yang ergonomis agar kenyamanan pengguna ketika menggunakan produk terjamin. Ergonomi disini adalah kenyamanan dan keamanan yang diperlukan untuk melakukan aktivitas dengan produk charging station yaitu dengan menggunakan material yang tidak berbahaya untuk menghindari adanya sudut-sudut yang tajam pada setiap sisinya.

Setelah studi aktivitas dan kebutuhan produk, maka dapat ditentukan anthropometri yang perlu digunakan untuk produk charging station sehingga dapat suatu batasan dimensi produk. Anthropometri yang dibutuhkan, yaitu :

Tinggi charger menggunakan dimensi ukuran jangkauan tangan penca- 
Vol. 5, No. 2, April 2018

paian kabinet wanita, yaitu dengan tinggi $175,3 \mathrm{~cm}$ maksimal. Sehingga tinggi yang digunakan adalah $90 \mathrm{~cm}$ dari lantai. Tinggi tersebut diasumsikan pada saat peletakan smartphone saat di charge.

Lebar charging station menggunakan $50 \%$ persentil wanita Hongkong dengan range vision optimum $118 \mathrm{~cm}$ untuk lebar maksimal produk. Sehingga ukuran yang digunakan adalah $50 \mathrm{~cm}$. ukuran tersebut diasumsikan sebagai lebar charging station untuk lebar space iklan yang berukuran $25 \mathrm{~cm}$ dan tinggi $37 \mathrm{~cm}$.

\subsection{Analisis Konfigurasi}

Analisis konfigurasi dilakukan untuk mendapatkan susunan atau konfigurasi dari tiap-tiap komponen yang terdapat pada charging station. Untuk mengetahui apa saja dan bagaimana perancangan charging station sesuai dengan data pengguna, maka perlu mengetahui gambaran atau denah produk tersebut.

Dari beberapa alternative konfigurasi, terpilih analisis yang ditunjukkan dalam gambar 1. Dalam konfigurasi gambar 1 tersebut, posisi charger dan meja peletakan smartphone berada di tengah. Peletakkan charger, meja peletakan smartphone tersebut akan memberikan kemudahan bagi pengguna apabila hendak mengisi daya baterai sekaligus melihat iklan dan logo dengan peletakannya yang berada di atas dengan ketinggian yang tepat sehingga membuat pengguna lebih leluasa dan nyaman dalam melakukan aktivitasnya.

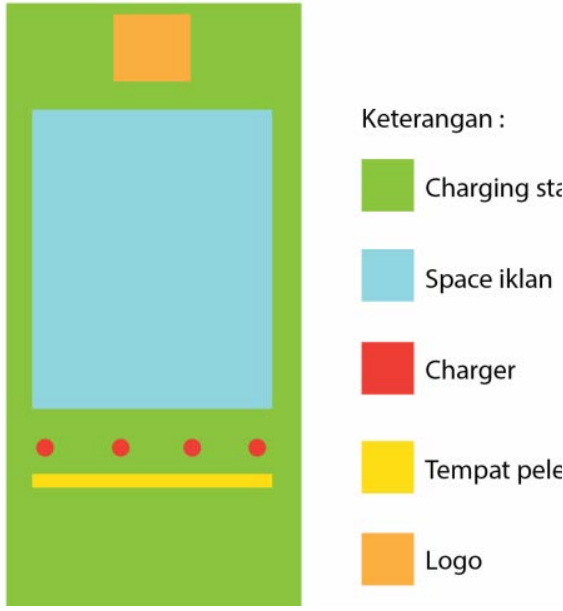

Gambar 1. Alternatif Konfigurasi terpilih

\subsection{Analisis Sistem}

Analisis sistem dilakukan guna mencari sistem yang efisien dan baik digunakan pada produk. Berdasarkan item penilaian yang menjadi tolak ukur dalam analisis sistem sebagai berikut :

\section{System sambungan}

Dari analisis sistem sambungan kayu di atas maka yang dipilih untuk diaplikasikan pada produk pengisi daya ponsel ini adalah sambungan jenis Butt Joints, yaitu sistem menyambung kayu membentuk siku. Sistem ini memiliki kelebihan yang paling mudah dilakukan sehingga paling banyak digunakan dalam proses produksi.

\section{System engesel}

Untuk bagian Hardware-Nya menggunakan Engsel Sendok karena berdasarkan berbagai pertimbangan yang telah disebutkan item-item pada sistem di atas.

\section{Sistem perekat akrilik dengan kayu}

Dari beberapa analisis sistem sambungan akrilik dengan kayu, maka sistem perekat dengan Lem Akrilik yang dipilih untuk diaplikasikan pada perancangan produk charging station ini karena sistem sambungan menggunakan Lem Akrilik lebih muda digunakan pada proses pengerjaanya 
dan lebih cocok untuk menguhubungkan komponen-komponen yang sifatnya permanen.

\section{Sistem perekat kayu dengan kayu}

Dari beberapa analisis sistem sambungan kayu dengan kayu, maka sistem perekat dengan kayu yang dipilih untuk diaplikasikan pada perancangan produk pengisi daya ponsel ini adalah Lem PVA karena sistem sambungan menggunakan Lem PVA lebih mudah digunakan pada proses pengerjaanya dan lebih cocok untuk menguhubungkan komponen-komponen yang sifatnya permanen.

\subsection{Analisis Material}

Analisis material dilakukan untuk menentukan material yang sesuai untuk diaplikasikan pada produk charging station yang akan dibuat. Berdasarkan analisis material yang btelah dilaksanakan, maka material utama yang terpilih adalah material kayu olahan jenis multipleks dan triplek karena memiliki nilai paling tinggi. Kayu multipleks dan triplek dipilih karena merupakan kayu olahan yang relatif kuat. Tekstur lapisan kayu yang lebih rapat, sehingga memiliki kekuatan yang lebih baik.

Sedangkan untuk material pendukung menggunakan Akrilik dan Alumunium. Untuk material finishing yang terpilih adalah Duco. Untuk bagian yang lain menggunakan LED Strip, LED spotlight, kabel power, kabel socket, kabel lampu dan stop kontak.

\subsection{Analisis Bentuk}

Analisis bentuk diperlukan dalam menentukan bentuk yang sesuai yang diterapkan pada produk. Berdasarkan beberapa pendekatan bentuk yang telah dianalisis, dipilih bentuk sederhana karena charger yang simpel yang terdiri dari beberapa komponen seperti adaptor dan kabel. Selain sederhana charging station juga mengandung unsur teknologi dan lifestyle karena charging station merupakan kebutuhan masa kini.

Dari hasil analisis gaya desain yang dilakukan, maka di dapatkan gaya desain Modern. Penggabungan aksen etnik yang dimodifikasi modern dengan gaya desain modern merupakan pendekatan bentuk yang akan di terapkan pada pembuatan produk tugas akhir ini karena dirasa tepat untuk perancangan charging station yang bergaya modern namun memiliki aksen etnik khas Kalimantan.

\subsection{Analisis Warna}

Analisis Warna diperlukan guna mendapatkan warna yang sesuai atau cocok dengan konsep yang diambil. Dengan konsep desain sarana Charging station Direktorat Politeknik Negeri Samarinda.

Berdasarkan analisis warna yang dilakukan, dari 10 kuesioner yang berisi palet warna, dengan ketentuan bebas untuk memilih berapa banyak warna yang di sukai, maka terpilihlah 3 warna teratas diantaranya Hijau, Abu-abu Tua, dan Abu-abu Muda. 
Vol. 5, No. 2, April 2018

\subsection{Hasil desain}

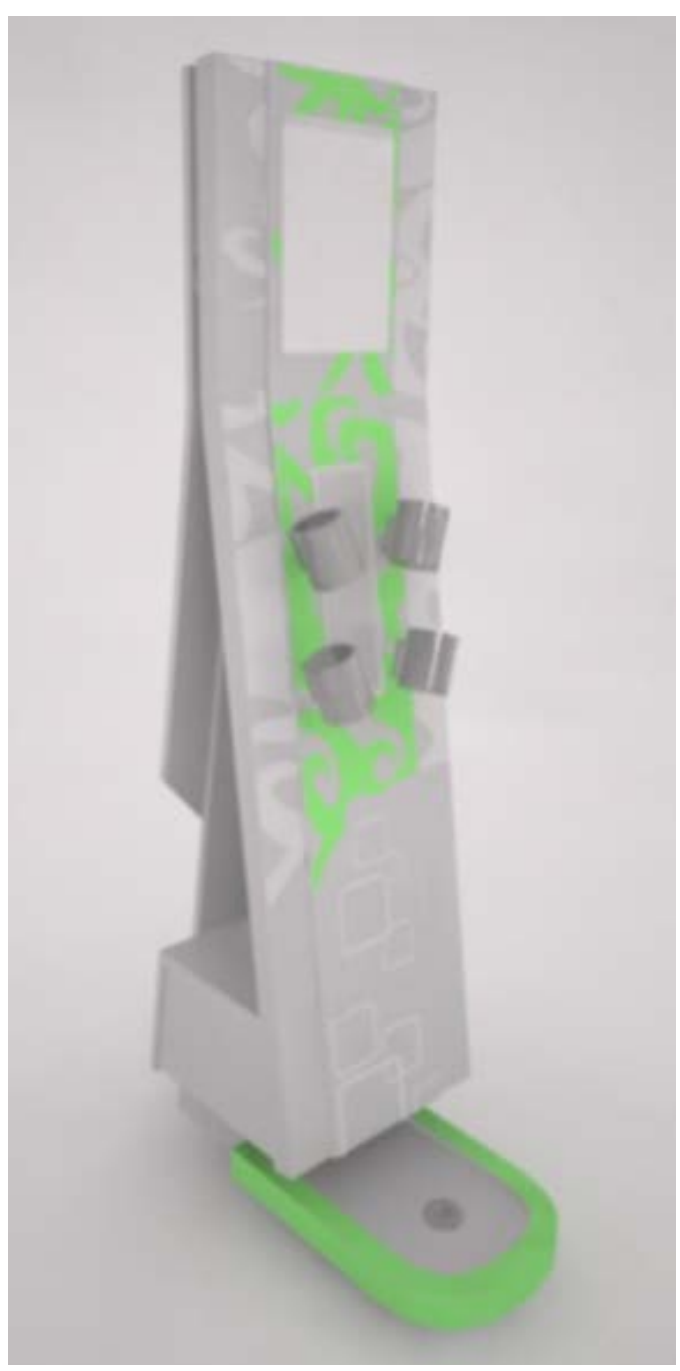

Gambar 2. Modelling produk

\section{Kesimpulan}

Berdasarkan hasil perancangan dan pembuatan "Desain Sarana Pengisi Daya Ponsel di Direktorat Politeknik Negeri Samarinda" maka dapat ditarik kesimpulan sebagai berikut :

Pengisi daya ponsel ini menggunakan konsep gaya Modern, dengan menggunakan warna identitas Politeknik Negeri Samarinda yaitu hijau dan abu- abu sebagai dominan.

Tujuan pada perancangan pengisi daya ponsel untuk pengunjung Rektorat Politeknik Negeri Samarinda ini adalah merancang sebuah tempat sebagai sarana pengisian baterai smartphone untuk pengunjung Rektorat Politeknik Negeri Samarinda yang nyaman sehingga lebih efektif digunakan dan dapat digunakan dalam jangka panjang. Saran yang dapat diberikan adalah bagi para produsen dan desainer agar perlu diadakan re-design untuk inovasi system pengisi daya ponsel untuk pengunjung Direktorat Politeknik Negeri Samarinda. Serta fungsi yang dapat disesuaikan dengan keinginan konsumen 


\section{DAFTAR RUJUKAN}

Berlo, David K, (1960). The Process of Communication: An Introduction to Theory and Practice. New York: Holt, Rinehart, and Winston Darmaprawira W.A, Sulasmi. (2002). Warna, Teori dan Kreativitas Penggunanya. Bandung: Penerbit ITB

Nurmianto Eko, (1998). Ergonomi Konsep Dasar dan Aplikasinya. Edisi Pertama Cetakan Kedua. Jakarta: Guna Widya

Panero Julius, AIA, ASID dan Zelnik Martin, AIA, ASID. (2003). Dimensi manusia dan ruang interior. Jakarta: Erlangga

Royan, Frans M, Marketing celebrities: Dalam Iklan dan Strategi Selebriti Memasarkan Diri Sendiri, PT Elex Media Kompuindo, Jakarta, 2007, Diunduh tanggal 8 Januari 2018 (http://digilib.isi.ac.id/538/4/bab\%204.pdf)

Santoyo S.E, Drs. (2005). Dasar-dasar Tata Rupa \& Desain. Yogyakarta: Arti Bumi Intaran Sunarto Wagiono. (2013). Gaya Desain Tinjauan Sejarah. Jakarta: Pascasarjana IKJ Supriyadi. (2014). Buku Ragam Hias Ornamen Khas Kaltim .Samarinda:Dinas Perindagkop dan UKM Provinsi Kalimantan Timur.

Tarwaka, Solichul Ha Bakri, Lilis Sudiajeng. (2004). Ergonomi Untuk Keselamatan, Kesehatan Kerja dan Produktivitas. Surakarta: Universitas Brawijaya Press.

Oentoeng, Ir. (2004). Konstruksi Baja. Yogyakarta: Andi. 